\title{
Using a Critical Incident-centered Transition Theory Framework to Explore Engineering Education Research Faculty Transitions
}

\author{
Dr. Alexandra Coso Strong, Franklin W. Olin College of Engineering
}

Alexandra Coso Strong is an assistant professor of systems design and engineering at Franklin W. Olin College of Engineering. Prior to starting a faculty position at Olin, she was a Postdoctoral Fellow at Georgia Tech's Center for the Enhancement of Teaching and Learning. She completed her Ph.D. in 2014 in Aerospace Engineering at Georgia Tech. Alexandra received her B.S. in Aerospace Engineering from MIT and her M.S. in Systems Engineering from the University of Virginia. Her research interests include engineering design education (especially in regards to the design of complex systems), faculty development, career pathways (both academic and industry), approaches for supporting education research-to-practice.

\section{Dr. Courtney S. Smith-Orr, University of North Carolina, Charlotte}

Courtney S. Smith,PhD is a Teaching Assistant Professor and Undergraduar Director at UNC Charlotte. Her research interests span the mentoring experiences of African American women in engineering,minority recruitment and retention, and best practices for diversity and inclusion in the Engineering classroom.

\section{Dr. Cheryl A. Bodnar, Rowan University}

Cheryl A. Bodnar, Ph.D., CTDP is an Assistant Professor in the Department of Experiential Engineering Education at Rowan University. Dr. Bodnar's research interests relate to the incorporation of active learning techniques in undergraduate classes as well as integration of innovation and entrepreneurship into the engineering curriculum. In particular, she is interested in the impact that these tools can have on student perception of the classroom environment, motivation and learning outcomes. She obtained her certification as a Training and Development Professional (CTDP) from the Canadian Society for Training and Development (CSTD) in 2010, providing her with a solid background in instructional design, facilitation and evaluation. She was selected to participate in the National Academy of Engineering (NAE) Frontiers of Engineering Education Symposium in 2013 and awarded the American Society for Engineering Education Educational Research Methods Faculty Apprentice Award in 2014.

\section{Dr. Walter C. Lee, Virginia Tech}

Dr. Walter Lee is an assistant professor in the Department of Engineering Education and the assistant director for research in the Center for the Enhancement of Engineering Diversity (CEED), both at Virginia Tech. His research interests include co-curricular support, student success and retention, and diversity. Lee received his Ph.D in engineering education from Virginia Tech, his M.S. in industrial \& systems engineering from Virginia Tech, and his B.S. in industrial engineering from Clemson University.

\section{Dr. Courtney June Faber, University of Tennessee, Knoxville}

Courtney is a Research Assistant Professor and Lecturer in the Cook Grand Challenge Engineering Honors Program at the University of Tennessee. She completed her Ph.D. in Engineering \& Science Education at Clemson University. Prior to her Ph.D. work, she received her B.S. in Bioengineering at Clemson University and her M.S. in Biomedical Engineering at Cornell University. Courtney's research interests include epistemic cognition in the context of problem solving, and researcher identity.

\section{Dr. Erin J. McCave, University of Houston}

Erin is an Instructional Assistant Professor in the Cullen College of Engineering at the University of Houston. She joined the University of Houston after completing a postdoctoral/lecturer position split between the General Engineering program and the Engineering \& Science Education Department and a Ph.D. in Bioengineering from Clemson University. Erin's research interests include preparing students for their sophomore year, minority student engineering identity development, and providing mentoring relationships to help foster student growth and success. 


\title{
Developing a Critical Incident-Centered Transition Theory Framework to Explore Engineering Education Research Faculty Transitions
}

\begin{abstract}
This methods paper describes the integration of critical incident techniques and Schlossberg's Transition Theory to create "incident timelines" that allow researchers to explore the transition of early career engineering education researchers into new faculty positions. In this methods paper, we demonstrate the usefulness of this approach by discussing the systematic development of our incident timeline analysis. We illustrate the methodological choices made to: 1) explore a diverse set of transitions into faculty positions, 2) identify critical events that impact these transitions, and 3) examine connections between events and strategies over time and across faculty members' transitions. Explorations of emerging and systematically developed methodologies will continue to expand the range of approaches available for use in engineering education research and further the community's ability to examine complex phenomena.
\end{abstract}

\section{Motivation}

Throughout the development of engineering education as a field, one thing has remained consistent: the interest for change, particularly curriculum development and pedagogical innovation [1]. Accordingly, more regular opportunities are presenting themselves for people to receive formal training in engineering education research. As these opportunities become more common, early career research faculty are increasingly aligning themselves with the field, presumptively orienting their career towards realizing impact in engineering education. While engineering education faculty may face challenges similar to those faced by other interdisciplinary scholars, such as negotiating legitimacy while attempting to impact the field and engineering education more broadly [2], this group is unique in that they are embedded within the system (i.e., engineering education) that they are trying to change.

Unfortunately, professional development opportunities for early career faculty that take this route are limited. To date, efforts to better prepare scholars for academic roles have primarily focused on preparing them to be independent researchers [3, 4], teach undergraduate courses [5-7], and support their ability to advance their career $[8,9]$, as opposed to impacting change more broadly. We argue that understanding the transition experiences of scholars aiming to impact change within engineering education is important for supporting sustained success.

\section{Purpose}

To address this gap in the literature, our team is examining the role of institutional context on the agency of early career engineering education faculty. As part of that larger study, we wanted to more closely examine our transitions, as early career engineering education researchers, into a diverse set of roles and institutions. In particular, we wanted to capture the significant events of our transition and isolate factors that impacted our experiences and agency as we worked within and towards our desired impact areas. The purpose of this paper is to describe the corresponding methodological decisions, particularly the integration of critical incident technique [10] and Schlossberg's Transition Theory [11-13] to create "incident timelines" capable of examining the transition of early career engineering education researchers into new faculty positions.

Studying transitions is particularly difficult for several reasons, which is why it requires a novel approach. First, asking questions after-the-fact may not elicit information about how people were experiencing a situation in the moment, as people often forget or distort events. Second, people 
may be reluctant to share certain information, particularly in a situation where interviews would either be conducted by another faculty member or a graduate student. Third, the significance of an event can be misunderstood if not interpreted in context or in relation to other elements in a person's life at the time of the event. And lastly, the transition into an academic position occurs over time and, thus, an approach that is largely cross-sectional may only offer a snapshot of the experience. In response to these circumstances, our aim is to demonstrate the usefulness of our methodological approach by highlighting the details of our incident timeline analysis.

\section{Study Background}

We, the authors, represent the six faculty participants that were involved in this study. Each of us provide a different perspective on transitioning to a faculty role due to our diverse set of backgrounds and training as well as the nature of our positions. Three of us were formally trained in engineering education research through doctoral education programs; two developed engineering education knowledge and practices through exposure as part of our doctoral and post-doctoral program work; and one of us developed the knowledge and practices while in a faculty position. In our new faculty positions, we represent both tenure and non-tenure track roles and have positions that are within a range of programs.

To examine the impact of institutional context on our agency, we selected and implemented aspects from both collaborative autoethnography and collaborative inquiry to study the experiences of our research team $[14,15]$. Throughout the first two years of our positions, we wrote weekly, monthly, pre-semester, and post-semester reflections to capture and make sense of our experiences. These reflections were completed concurrently with weekly virtual meetings to discuss/make sense of our experiences. Further discussions of the collaborative autoethnography and collaborative inquiry methodologies can be referenced in previous publications [14].

To conduct a more focused investigation of our transitions, however, we needed to make particular theoretical and analytical research design decisions to explore the transition data using a different lens. The purpose of this paper is to discuss these methodological decisions and describe how we integrated aspects of a theoretical framework and a data collection/analysis technique to develop incident timelines. We selected Scholossberg's Transition Theory as our guiding theoretical framework. Due in part to the complexity of a transition into a faculty position, especially at diverse institutional contexts, it was necessary to determine the extent to which particular events and the relationship between events impacted a new faculty member's experience. To accomplish this, we integrated the Critical Incident Technique with Transition Theory to specifically investigate individual events that were considered significant to the overall transition, ultimately leading to the development of an incident timeline. The subsequent sections will illustrate this integration and the methodological choices that allow us to:

- Explore a diverse set of transitions into faculty positions;

- Identify critical events that impact these transitions; and

- Examine connections between events and strategies over time and across faculty members' transitions.

Preliminary results will be shared to illustrate the application of this methodology, along with a discussion of strengths and limitations of this methodological approach.

\section{Methodological Decisions}

To develop and explore the incident timelines, we used a multiple case study approach [16], where each faculty member represented a case. Data focused on the first two years of the faculty 
experience and the analysis was conducted through an iterative within-case and cross-case process. Because researchers were also participants, cross-case meaning making occurred informally throughout the process. The Q3 qualitative research framework $[17,18]$ was used to guide the research design, establishing validity and reliability of the data collection (making the data) and analysis (handling the data) early and throughout our process. The following sections explore three critical choices that were made during the research design process: (1) Theoretical Framework Adaptation, (2) Data Selection and Filtering, (3) Analysis Process Design.

\section{Choice 1: Theoretical Framework}

As faculty members navigate the start of their academic careers, they have experiences, anticipated and unanticipated, that lead to adapting and developing as scholars, educators, and professionals. Schlossberg's Transition Theory provides a lens through which to explore how individuals identify and adapt based on these experiences or "transitions" in their lives [11-13]. An individual's transition, according to Schlossberg and colleagues, tends to include three phases: "moving in", or becoming familiar with the new roles and relationships brought on by the experience; "moving through", and becoming a full participant in the experience; and "moving out", or getting ready to exit the experience. Originally, this theory was created to describe transitions within adult development. In later works by Schlossberg and colleagues, the theory's applicability was expanded to a variety of populations. Transition theory has since been used in many contexts - for example, to explore doctoral students' pathways through extracurricular programming [19] and to study transitions and pathways of underrepresented, or understudied, students, such as student athletes [20] and veterans [21, 22]. Given our focus on early career faculty, we chose Transition Theory to examine our own experiences as we have changed our roles, routines, and professional relationships in the first years of our new positions.

Over the phases of a transition, an individual's experiences are influenced by the context of the transition, the characteristics of the individual such as their motivations and beliefs, the extent to which they have support, and the strategies they utilize. These factors, known as the 4S System $[12,23]$, are defined as follows:

- $\quad$ situation - the individual's situation at the time of transition,

- self - the individual's personal characteristics that could impact how they perceive the transition, including psychological resources [23] (e.g., ego development, outlook, selfefficacy, values, etc.)

- $\quad$ support - the social supports that the individual engages with during the transition, and

- strategies - the ways in which the individual interacts with the transition, including whether and how they aim to modify, reframe, or reduce stress caused by the situation.

Traditionally, the 4Ss are explored at each phase of a transition. The transition into a faculty position, however, may not have clear phases, and phases may exist for sub-parts of the faculty position (e.g., becoming an instructor-of-record for the first time). Therefore, we chose to not assume that specific phases happen at particular times or would be the same for each member of the research team. Instead, we decided to capture information about the 4Ss at critical points during our transitions. As a result, the 4Ss informed our iterative data analysis process to describe factors affecting and affected by critical incidents.

\section{Choice 2: Data Selection and Filtering}

We applied our approach to the monthly and pre- and post-semester reflections. In the monthly reflections, each participant provided their impressions of the faculty role, in what ways they felt 
like a faculty member, and in what ways they did not. By focusing on less frequent reflections, we aimed to capture those particularly significant events that impacted one's impressions of the faculty role, one's relationships with others, and one's routines. Given that it was unlikely the reflections would identify every important event during an individual's transition, we designed an activity for each member of our team to complete at the end of their second year. Each member created their own timeline capturing critical incidents that reflected their transition over the previous two years. This timeline was constructed based on our memory of our experiences and occurred without referencing any of our prior reflections. Once an initial draft of the timeline was created, we each went back and reviewed our monthly and pre- and post-semester reflections, modifying our own timeline as we felt was necessary.

We used the Q3 framework to review our data collection strategies and ensure that we were collecting data in a reliable manner. Table 1 provides an overview of how our data collection strategies met each element of the framework, where the italicized text represents the definitions as defined in the framework and the bulleted lists represent our strategies.

\section{Choice 3: Analysis Process Design \\ Critical Incident Technique}

Critical incident analysis is a technique that has been used in various fields to provide individuals with the opportunity to reflect on their experiences and explain their actions. Critical incidents are defined by Flanagan (1954) as "any observable human activity that is sufficiently complete in itself to permit inferences and predictions to be made about the persons performing the act” (p.1). This analysis method uses flexible principles that help "data to be sorted into patterns or relationships, and then summarized and described effectively” [10] (p.1). For our study, we reviewed reflections from our first two years as faculty to identify events that were critical to our transition. For an incident to be judged as critical, it "must occur in a situation where the purpose or intent of the act seems fairly clear to the observer and where its consequences are sufficiently definite to leave little doubt concerning its effects” [10] (p.1).

Critical incident analysis has been used previously within engineering education. Grant and Trenor (2010) used critical incident technique to guide them in developing an interview protocol for exploring first generation college students' interactions with their parents [24]. This technique proved helpful because it assisted with identifying factors that could be important in understanding how family influenced these students. The data obtained provided examples of these incidents and detailed information about behaviors as well. More recently, critical incident technique has been used to examine the educational pathways of adult makers [25] and how practicing engineers are expected to work in contexts that span boundaries [26]. Due in part to the complexity of a transition into a faculty position, we incorporated this method to isolate the events and the relationship between events that impact a new faculty member's experience.

\section{Integrated Analysis Process}

We used an iterative data analysis process to develop an incident timeline for each participant (see Figure 1). To mitigate potential threats to validity and reliability, procedures were developed for handling the data using the Q3 Framework (see Table 2). Given the researcher-participant roles of each author, we aimed to: (1) enable analysis that focused on data generated by someone else, representing an "outsider" view; (2) allow the participant to collaboratively make sense of their own data with other members of the team, representing the "insider" view. As a result, we each switched roles throughout the process. Within the paper, subject will be used to refer to the 
individual who wrote the reflections of their own experience, and observer will refer to the member of the research team providing the perspective of the "outsider looking in" [27].

Table 1: Description of how the Q3 Framework $[17,18]$ was applied to the data collection process

\begin{tabular}{|c|c|}
\hline Description & Making Data \\
\hline $\begin{array}{l}\text { Theoretical Validation } \\
\text { Do the concepts and } \\
\text { relationships of the theory } \\
\text { appropriately correspond to } \\
\text { their social reality under } \\
\text { investigation? }\end{array}$ & $\begin{array}{l}\text { The research process needs to be able to capture the full extent of the social } \\
\text { reality studied. } \\
\text { - The team reviewed basics of transition theory literature } \\
\text { - Created data files that encompassed reflections pertaining to "How do } \\
\text { - } \text { Usu feel like a faculty member?" } \\
\text { based on reflections from Years } 1-2\end{array}$ \\
\hline $\begin{array}{l}\text { Procedural Validation } \\
\text { Which features of the research } \\
\text { design improve the fit between } \\
\text { reality and the theory } \\
\text { generated? }\end{array}$ & $\begin{array}{l}\text { Strategies need to be implemented in the research design to mitigate threats to } \\
\text { contextual validation. } \\
\text { - Individuals had questions pertaining to "How do you feel like a faculty } \\
\text { member?” included in their normal reflections } \\
\text { - Leveraged reflections that were written during the semester and } \\
\text { follow-up 'interviews' to mitigate threats of getting an authentic view. }\end{array}$ \\
\hline $\begin{array}{l}\text { Communicative Validation } \\
\text { Is the knowledge socially } \\
\text { constructed within the relevant } \\
\text { communication community? }\end{array}$ & $\begin{array}{l}\text { The data gathering needs to capture the respondents' inter-subjective reality. } \\
\text { - Each individual separately constructed their own timeline and then } \\
\text { modified it on the basis of their personal reflections } \\
\text { - Meetings between researcher pairings and individuals to co-construct } \\
\text { final timeline } \\
\text { - The individual and researcher pairings both took notes to maintain the } \\
\text { meaning constructed throughout our analysis }\end{array}$ \\
\hline $\begin{array}{l}\text { Pragmatic Validation } \\
\text { Do the concepts and } \\
\text { knowledge claims withstand } \\
\text { exposure to the reality } \\
\text { investigated? }\end{array}$ & $\begin{array}{l}\text { The concepts underlying the research design need to be compatible with reality } \\
\text { in the field. } \\
\text { - Creation of timeline through identification of critical incidents } \\
\text { - Focused on the first two years of the transition period for EERs to } \\
\text { provide value to the broader EER community } \\
\text { The group includes individuals from diverse institutional contexts and } \\
\text { positions }\end{array}$ \\
\hline $\begin{array}{l}\text { Ethical Validation } \\
\text { Does our research do justice to } \\
\text { all stakeholders? }\end{array}$ & $\begin{array}{l}\text { The research process should meaningfully and equitably engage all members of } \\
\text { the research team. } \\
\text { - Discussed with entire team which individuals would like to take part in } \\
\text { transition theory work and moved forward with creating research } \\
\text { pairings based on interest in project participation }\end{array}$ \\
\hline $\begin{array}{l}\text { Process Reliability } \\
\text { How can the research process } \\
\text { be made as independent as } \\
\text { possible from random } \\
\text { influences? }\end{array}$ & $\begin{array}{l}\text { The data needs to be collected and recorded in a dependable way. } \\
\text { - Background activity and data analysis plan documents that outline all } \\
\text { steps of the research process } \\
\text { - Created a separate data file that just contains questions of interest for } \\
\text { the focus of this study }\end{array}$ \\
\hline
\end{tabular}


The first phase entailed a subset of the research team identifying an initial set of critical incidents for each individual. These observers reviewed critical incident literature to understand what types of events, activities or actions could be considered "critical." Then each observer read through three sets of reflections (none of which was their own). Two observers were assigned each subject's reflection, coding independently. The observers identified evidence of critical incidents within the individual person's transition, noting details about the incident (e.g., cause and effects) and any questions they may have about the incident or its effects.

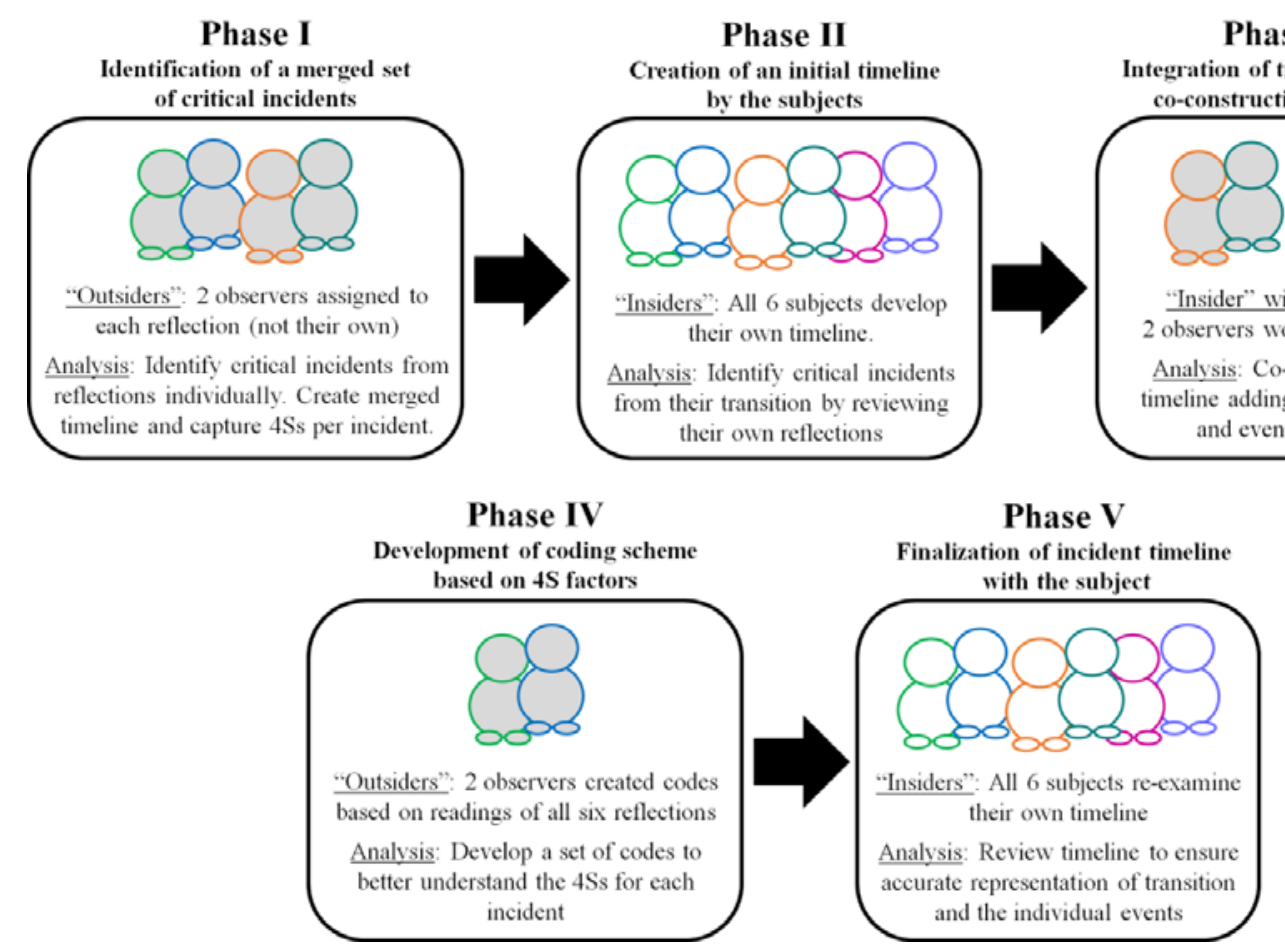

Figure 1: Iterative analysis process engaging the subjects in the analysis

Upon completing this initial identification of critical incidents, the observers met in pairs to discuss and merge the coding into a single document. Particularly, the observers examined each critical point and using the $4 \mathrm{Ss}$ as a guide, captured quotes to describe the characteristics of the incident. Any questions about the transition, the critical points, and the 4S factors were also recorded.

The second phase of the analysis engaged the subject within the development of their own timeline. Each member of the team created a bulleted list identifying a timeline of critical incidents for their personal transition. Then, they each read through their own set of reflections, as described in the data sources subsection, and modified the initial list as necessary. During the third phase of the analysis, each subject met with the pair of observers assigned to reading their reflection to co-construct a final timeline. These co-construction interviews allowed us to explore each event in more detail and provided an opportunity for reflection-on-action by the subject.

In particular, observers used in vivo coding to develop codes for the situations, process coding to create an action list of strategies and supports for each individual, and a variation of emotion coding to explore self, especially the psychological resources for each situation [28]. The two

Table 2: Description of how the Q3 Framework $[17,18]$ was applied to the data analysis process 


\begin{tabular}{|c|c|}
\hline Description & Handling the Data \\
\hline $\begin{array}{l}\text { Theoretical Validation } \\
\text { Do the concepts and } \\
\text { relationships of the } \\
\text { theory appropriately } \\
\text { correspond to their } \\
\text { social reality under } \\
\text { investigation? }\end{array}$ & $\begin{array}{l}\text { Findings should make a meaningful contribution to the relevant body of theory and } \\
\text { interpretations need to reflect the coherence and complexity of the social reality under } \\
\text { investigation. } \\
\text { - The team conducted a detailed review of transition theory and faculty } \\
\text { transitions to determine gaps that exist in the literature. } \\
\text { - Data analysis results align with transition theory and critical incident } \\
\text { technique. }\end{array}$ \\
\hline $\begin{array}{l}\text { Procedural Validation } \\
\text { Which features of the } \\
\text { research design improve } \\
\text { the fit between reality } \\
\text { and the theory } \\
\text { generated? }\end{array}$ & $\begin{array}{l}\text { Processes need to be implemented to mitigate risks of mis-constructing the } \\
\text { participants' reality in the researcher's interpretations. } \\
\text { - Created researcher pairings to review each subject's data set and create a } \\
\text { timeline and then had each subject create their own timeline. Observer pairs } \\
\text { and subject then came together to allow for co-construction of final timeline. } \\
\text { - Memos and an audit trail were created to capture the analysis process and } \\
\text { make note of any changes. }\end{array}$ \\
\hline $\begin{array}{l}\text { Communicative } \\
\text { Validation } \\
\text { Is the knowledge } \\
\text { socially constructed } \\
\text { within the relevant } \\
\text { communication } \\
\text { community? }\end{array}$ & $\begin{array}{l}\text { Interpretations need to be grounded in the accounts of the participants. The knowledge } \\
\text { produced needs to be represented in accordance with the meaning conventions of the } \\
\text { research community. } \\
\text { - Will use our detailed literature review to help determine how to present our } \\
\text { results to the broader engineering education community. } \\
\text { - Conducted additional member checking events for subjects to review their } \\
\text { own timelines and the related prose as we move closer to a publication. } \\
\text { - Will reference existing literature on faculty transitions during our writing. }\end{array}$ \\
\hline $\begin{array}{l}\text { Pragmatic Validation } \\
\text { Do the concepts and } \\
\text { knowledge claims } \\
\text { withstand exposure to } \\
\text { the reality investigated? }\end{array}$ & $\begin{array}{l}\text { The knowledge produced needs to be meaningful in the social context under } \\
\text { investigation. } \\
\text { - To ensure the Transition Theory constructs survive the social reality we kept } \\
\text { the theory separate from the reflection until the person had reflected and } \\
\text { created their own timeline of their transition. } \\
\text { - Leveraged critical peers to determine how meaningful our interpretations are } \\
\text { for the social reality under investigation. }\end{array}$ \\
\hline $\begin{array}{l}\text { Ethical Validation } \\
\text { Does our research do } \\
\text { justice to all } \\
\text { stakeholders? }\end{array}$ & $\begin{array}{l}\text { Our process should meaningfully and equitably engage all members of the research } \\
\text { team. The findings need to do justice to the lived realities of our participants. } \\
\text { - Will construct a vulnerability statement that outlines what we are comfortable } \\
\text { with sharing in a final product. } \\
\text { - Everyone will review the final draft of the manuscript and approve prior to } \\
\text { submission; and be involved in the creation and narration of their own } \\
\text { transition timeline. }\end{array}$ \\
\hline $\begin{array}{l}\text { Process Reliability } \\
\text { How can the research } \\
\text { process be made as } \\
\text { independent as possible } \\
\text { from random } \\
\text { influences? }\end{array}$ & $\begin{array}{l}\text { Procedures for generating and representing knowledge need to be established and } \\
\text { documented. } \\
\text { - Researcher pairings created separate documents for each of their reviews of } \\
\text { the data set, these were then co-constructed into a single document. } \\
\text { - Each individual created a separate document of their personal timeline. }\end{array}$ \\
\hline
\end{tabular}

observers met to discuss the codes they created, expanding or condensing codes as needed. The resulting codebook was used to code the remaining reflections, before the observers met a final time to revise the codebook. 
The final phase of the analysis re-integrates the subject of the timeline as part of the analysis to ensure the codes were accurate representations of the events and how they were connected. The resulting timelines were examined visually to explore connections between events and strategies over time and cross-case to identify overarching themes common to these types of faculty transitions. Preliminary results of the timeline development are presented in the subsequent section to illustrate how this methodology can be applied.

\section{Implementation \& Discussion: Iterative Analysis Process}

Through the iterative critical incident timeline analysis process, we were able to explore a diverse set of transitions into faculty positions and identify critical events that impact those transitions. The final stages of the data analysis process isolated strategies and supports that aided the faculty members in different aspects of their transitions. The visual timelines will enable future work to explore the within and cross-case connections between events and strategies. This section will illustrate, through the use of two examples, how the iterative process led to an incident record on an incident timeline and how that record supports an analysis of the transition experience. To maintain the authenticity of the subject's voice in the example, direct quotes were used when possible and only minor modifications were made to keep the identity of the subject confidential.

For example, early on in their faculty position, one of the researchers in this study, Dr. North, responded to the question In what ways do you feel like a faculty member? In what ways do you not feel like a faculty member? with the following response:

People treat you differently as a faculty member at conferences. They want to find ways to collaborate. Students talk to you. It's just different. Your ideas are valued more and competence is at least assumed initially. I still don’t have students, or a funded project. I feel like a faculty member otherwise though.

Both of the observers noted this as a critical point for this faculty member, and one commented in their notes, "I believe that the way that people treat [Dr. North] and view [them] has an impact on [their] perception of [themselves] and [their] role as a faculty member.”

In the merged incident document, the two observers created the following description of the incident and the self, support, and strategies that were relevant to the incident. The observers' questions for Dr. North were also included.

"People treat you differently as a faculty member at conferences."

Situation: "People treat you differently as a faculty member at conferences. They want to find ways to collaborate. Students talk to you. It’s just different.” (permanent change in role at conferences)

Self: "It's just different. Your ideas are valued more and competence is at least assumed initially."

Support: Did you receive advice on how to approach conferences as a faculty member?

Strategies: Did you approach presenting at a conference any differently knowing that you are a faculty member? How did you introduce yourself in comparison to as a graduate student?

When Dr. North developed their own timeline, they included their attendance at a conference that semester as a critical incident from their perspective. In the co-construction interview, the observers and Dr. North expanded on the descriptions of the 4Ss and renamed the incident based 
on Dr. North's naming of the incident in their timeline. Additional quotes from the discussion were added to incorporate more of Dr. North's voice when describing the incident.

\section{Attended [Conference] as a faculty member}

"People treat you differently as a faculty member at conferences."

Situation: "People treat you differently as a faculty member at conferences. They want to find ways to collaborate. Students talk to you. It's just different.” (permanent change in role at conferences). "The [other university] graduate students were way friendlier. It was like the graduate students from other departments suddenly realized you are a faculty member."

Self: "It's just different. Your ideas are valued more and competence is at least assumed initially.” They noticed that people talked to them differently.

Support: They did not receive any advice on how to approach attending [this conference] as a faculty member.

Strategies: They didn't feel that they did anything different at this conference. They were floating around and interacting with people (no recollection if they presented or not).

When this incident was coded in the next phase of the analysis, the observers noticed that more than one faculty member mentioned attending their first conference as a faculty member. Thus, the final entry in Dr. North's incident timeline for this event is recorded as follows:

\section{Year 1 - First Semester \\ Attended Conference as Faculty \\ "People treat you differently as a faculty member at conferences." \\ Shift in relationships with members of field \\ Resulted in positive outlook \\ No supports or specific strategies were used}

The second example comes from the second semester in the team's faculty transition. One of the team members, Dr. South, responded to the same question as Dr. North, In what ways do you feel like a faculty member? In what ways do you not feel like a faculty member?, with the following response:

The only thing keeping me from fully feeling like a faculty member is the research aspect. While I'm in a position that is focused on teaching, I still want to do research and better understand the student population I am teaching.

Both of the observers did not note any critical incidents during this month for Dr. South.

When Dr. South created their own timeline, they created an event in their timeline to capture their attendance at an engineering-related outreach trip. In their timeline they added a side note which provided a bit of their reflection-on-action as they thought back through those important events during their first two years in their faculty position:

Side note: Made me miss doing research. Got me thinking more about how and what to study. The population is so diverse and the courses serve more than just engineering students as they are the pathway into engineering.

In the co-construction interview, the observers and Dr. South explored this outreach trip further to understand the incident in more detail and create descriptions for the 4Ss.

\section{Traveled for an Engineering-related outreach trip.}


"Got to participate in several STEM related events and talk with students about their experiences."

Situation: They went as a chaperone but actually participated in the activities. They felt like they did more than the other individuals that attended. Got into conversations about how you recruit students and keep them engaged. The group traveling was comprised of all females to focus on diversity in engineering, as such, Dr. South was asked to chaperone due to the population traveling for this outreach grant.

Self: They enjoyed having those conversations and learning more about context. They didn't know what to expect when going on the trip but was provided with a schedule.

"Side note: Made me miss doing research. Got me thinking more about how and what to study. The population is so diverse and the courses serve more than just engineering students as they are the pathway into engineering."

Support: Didn't end up missing any classes due to the travel. Their travel was covered by a grant.

Strategies: Brought supplies with them to run the booths that the students would have to go through.

When this incident was coded in the next phase of the analysis, the final entry in Dr. South's incident timeline for this event is recorded as the following:

\section{Year 1 - Second Semester Attended Conference}

"Got to participate in several STEM related events and talk with students about their experiences.”

Reminder of aspects of role currently underemphasized

Resulted in positive outlook, but revealed that they missed conducting research

Received financial support and didn't miss class.

These two examples showcase how a single event (e.g., attending a conference) can have a different impact on the early career faculty member. Dr. North experienced a shift in their relationships with others in the field, while Dr. South was reminded of aspects of their role that were missing from their daily routines. These examples also highlight how involving the subject in the analysis process permitted the team to uncover events that might not be in initial reflections (e.g., they may have only been perceived as significant later in the subject's experience). The co-construction activities, in particular, deepened both the observers' and the subject's understanding of the significance of a particular event within the context of the larger transition. These preliminary results illustrate how closer examination of these timelines will enhance our understanding of the supports and strategies used during professional transitions.

\section{Strengths \& Limitations}

This methodology was developed for a qualitative study of a small sample of early engineering education faculty. The iterative analysis process was intended to provide rich description of multiple experiences of faculty at diverse institutional contexts, and thus is a time-consuming methodology which seeks transferability, as opposed to generalizability. The data collected for this investigation were taken weekly over a two year span, however the decision to use only monthly and pre- and post-semester reflections for this analysis was intended to focus on incidents which were potentially more significant than those that occurred weekly. While this may have increased the chances of missing out on some pivotal incidents that were only included 
in the weekly reflection documents this was mitigated by including both insiders and outsiders in the analysis process and revisiting critical incidents by subjects. The interviews conducted to account for any potentially missed incidents required participants to reflect back over a span of two years where experiences may have been forgotten or become seen as less significant with so much retrospect. Importantly the characterization of incidents as "critical” and "significant" was determined by the faculty member and may have reduced the number of incidents identified by the research team. While each of these may have served as limitations to the study, the use of the Q3 framework mitigated challenges in the analysis process, particularly the closeness of the research team to participants (experience-near analysis).

\section{Conclusion \& Future Work}

This methods paper seeks to continue to extend the "methodological range" of engineering education research by demonstrating the systematic development and implementation of incident timelines, a variation of the critical incident approach and Transition Theory, for exploring complex professional transitions [29]. The use of the Q3 framework guided our research team in the process of (1) Theoretical Framework Adaptation, (2) Data Selection and Filtering, and (3) Analysis Process Design allowing us to explore the transition experiences of new engineering education faculty. Through the iterative and insider-outsider data collection and analysis process, a more comprehensive understanding of the experiences of early career engineering education faculty will be possible. Additionally, the implementation examples illustrate how this incident timeline analysis process might support other research aimed at examining the experiences of populations in transition. While the methods employed for this evaluation of faculty transitions provided a great deal of insight thus far, future work will explore the similarities and differences between our transitions and those of other early career engineering education faculty members as pragmatic validation. The team also plans to continue this work by exploring aspects of identity that have emerged from this data and their impact on the transition process and impact of new engineering education faculty.

\section{Acknowledgements}

This material is based upon work supported by the National Science Foundation under Grant Numbers 1663909, 1664217, 1664038, 1664016, 1664008, 1738262. Any opinions, findings, and conclusions or recommendations expressed in this material are those of the author(s) and do not necessarily reflect the views of the National Science Foundation.

\section{References}

[1] J. Froyd and J. R. Lohmann, “Chronological and Ontological Development of Engineering Education as a Field of Scientific Inquiry,” in Cambridge Handbook of Engineering Education Research, A. Johri and B. Olds, Eds. Cambridge University Press, 2014, pp. 3-28.

[2] L. D. Gonzales and R. Rincones, "Interdisciplinary scholars: negotiating legitimacy at the core and from the margins,” J. Furth. High. Educ., vol. 36, no. 4, pp. 495-518, 2012.

[3] S. K. Gardner, “'What's Too Much and What's Too Little?’: The Process of Becoming an Independent Researcher in Doctoral Education,” J. Higher Educ., vol. 79, no. 3, pp. 326-350, 2008.

[4] S. C. Narendorf, E. Small, J. A. B. Cardoso, R. W. Wagner, and S. W. Jennings, "Managing and Mentoring: Experiences of Assistant Professors in Working with Research Assistants,” Soc. Work Res., vol. 40, no. 1, pp. 19-30, 2016.

[5] A. E. Austin, H. Campa III, C. Pfund, D. L. Gillian-Daniel, and R. Mathieu, "Preparing STEM doctoral students for future faculty careers,” New Dir. Teach. Learn., no. 117, pp. 83-95, 2009.

[6] A. E. Austin, M. R. Connolly, C. Pfund, and L. J. Shelton, "Preparing to reach: The impact of the CIRTL 
(Center for the Integration of Research, Teaching, and Learning) professional development programs on future faculty,” in American Educational Research Association Annual Conference, 2013.

[7] J. Reeves et al., "Change agents: Immediately implementable teaching and educational hints from the engineering education scholars program," in American Society for Engineering Education Annual Conference and Exposition, 1999, pp. 1121-1134.

[8] M. Goller and C. Harteis, "Employing agency in academic settings: Doctoral students shaping their own experiences," in Discourses on Professional Learning: On the Boundary between Learning and Working, vol. 9, C. Harteis, A. Rausch, and J. Seifried, Eds. Springer Science, 2014, pp. 189-210.

[9] W. Jordan and B. Elmore, "Balancing professional and personal life to achieve significance in an academic career," in American Society for Engineering Education Annual Conference and Exposition, 2003.

[10] J. C. Flanagan, “The critical incident technique.,” Psychol. Bull., vol. 51, no. 4, pp. 327-358, 1954.

[11] N. K. Schlossberg, "A Model for Analyzing Human Adaptation to Transition,” Couns. Psychol., vol. 9, no. 2, pp. 2-18, Jun. 1981.

[12] N. K. Schlossberg, E. B. Waters, and J. Goodman, Counseling adults in transition: Linking practice with theory, 2nd ed., vol. 1. New York, NY: Springer Publishing Company, 1995.

[13] N. K. Schlossberg, "The challenge of change: The transition model and its applications,” J. Employ. Couns., vol. 48, no. December, pp. 159-162, 2011.

[14] C. Faber, C. Bodner, A. Coso Strong, W. Lee, E. McCave, and C. Smith, "Narrating the Experiences of First-year Faculty in Engineering Education Research Community: Developing a Qualitative, Collaborative Research Methodology," in American Society for Engineering Education Annual Conference and Exposition, 2016.

[15] C. J. Faber, C. S. Smith-Orr, W. L. Lee, C. A. Bodnar, A. Coso Strong, and E. McCave, "Best Practices for Developing a Virtual Peer Mentoring Community," in American Society for Engineering Education Annual Conference and Exposition, 2017.

[16] R. K. Yin, Case Study Research: Design and Methods, vol. 5. Newbury Park: Sage Publications, 1989.

[17] J. Walther, A. Pawley, and N. Sochacka, "Exploring Ethical Validation as a Key Consideration in Interpretive Research Quality," in American Society for Engineering Education Annual Conference and Exposition, 2015.

[18] J. Walther, N. W. Sochacka, and N. N. Kellam, "Quality in Interpretive Engineering Education Research: Reflections on an Example Study,” J. Eng. Educ., vol. 102, no. 4, pp. 626-659, Oct. 2013.

[19] A. E. Coso and D. Sekayi, "Exploring the role of institutional climate in preparing engineering doctoral students for academic careers," in American Society for Engineering Education Annual Conference and Exposition, 2015.

[20] R. D. Flowers, C. Luzynski, and E. M. Zamani-Gallaher, "Applying Schlossberg’s Transition Theory to Transfer Student Athletes," in Annual Meeting of the American Educational Research Association, 2013, pp. $1-39$.

[21] K. A. Griffin and C. K. Gilbert, "Better Transitions for Troops: An Application of Schlossberg's Transitions Framework to Analyses of Barriers and Institutional Support Structures for Student Veterns,” J. Higher Educ., vol. 86, no. 1, pp. 71-97, 2015.

[22] J. B. Main, M. M. Camacho, C. Mobley, and C. E. Brawner, "Using Focus Groups to Understand Military Veteran Students' Pathways in Engineering Education,” 2016.

[23] M. L. Anderson, J. Goodman, and N. K. Schlossberg, Counseling adults in transition: Linking Schlossberg's Theory with Practice in a Diverse World, 4th ed. New York: Springer Publishing Company, 2012.

[24] D. Grant and J. Trenor, "Use of the critical incident technique for qualitative research in engineering education: An example from a grounded theory study,” in American Society for Engineering Education Annual Conference and Exposition, 2010.

[25] M. Lande and S. S. Jordan, "Methods for Examining the Educational Pathways of Adult Makers," in American Society for Engineering Education Annual Conference and Exposition, 2014.

[26] B. K. Jesiek, N. M. Trellinger, and A. Mazzurco, "Becoming Boundary Spanning Engineers : Research Methods and Preliminary Findings," in American Society for Engineering Education Annual Conference and Exposition, 2016.

[27] S. C. Dwyer and J. L. Buckle, "The Space Between: On Being an Insider-Outsider in Qualitative Research,” Int. J. Qual. Methods, vol. 8, no. 1, pp. 54-63, 2009.

[28] M. Miles and A. M. Huberman, Qualitative Data Analysis. Beverly Hills, CA: Sage Publications, 1984.

[29] J. M. Case and G. Lighta, "Emerging Methodologies in Engineering Education Research,” J. Eng. Educ., vol. 100, no. 1, pp. 186-210, 2011. 